\title{
Access to Secure Ballot Drop-off Locations in Texas
}

\author{
Alex Karner ${ }^{1} \mathbb{Q}{ }^{\text {a }}$, Dana Rowangould ${ }^{2}$ (C) \\ ${ }^{1}$ Graduate Program in Community and Regional Planning, The University of Texas at Austin, ${ }^{2}$ Department of Civil and Environmental Engineering, University of \\ Vermont \\ Keywords: accessibility, voting, transport disadvantage, transportation equity \\ https://doi.org/10.32866/001c.24080
}

\section{Findings}

Safe access to voting during the Covid-19 pandemic was a concern across the US. In Texas, a push for mail-in voting during the November 2020 presidential election was significantly scaled back when the governor restricted each county to one secure ballot drop-off location. We evaluate the effect of this change, finding that it increased travel times to drop-off locations for drivers and public transit users by 18 and 32 minutes, respectively, in the most affected county. When evaluated across the state, the policy had a disproportionate effect on eligible Asian, Black, and Latinx voters.

\section{Questions}

Throughout the Covid-19 pandemic, voters have been justifiably concerned about contracting the virus at in-person polling locations. Accordingly, states and counties across the US raced to provide alternatives to election-day voting. In the November 2020 presidential election, over 100 million voters cast ballots early compared to 47 million in 2016 (McDonald 2021).

Texas is one of only five states that restricted mail-in ballots to voters meeting certain eligibility criteria (Rabinowitz and Mayes 2020). Mail-in ballots could be returned by regular mail or at a secure drop-off location in advance or on election day. As concerns about mail delays grew throughout 2020, all Texas counties planned for at least one drop-off location. Harris County-which contains Houston and is the most populous in the state-planned for 12 locations. Travis County, home to the state's capital city of Austin, planned for four centrally located drop-off sites.

On October 1, 2020, Texas Governor Greg Abbott issued an executive order limiting drop-off locations to one per county. This order was quickly challenged in court by those seeking to expand ballot access. Ultimately, the Texas Supreme Court ruled in favor of the order in late October 2020.

Changes to voting locations affect access to the polls and voting likelihood (Brady and McNulty 2011; Gimpel and Schuknecht 2003; Haspel and Knotts 2005; Morris and Miller 2021). Consequently, the decision to remove secure drop-off locations risks disenfranchising many Harris and Travis County 
voters, particularly those without vehicle access. Harris County was most affected because of the substantial change in the spatial distribution of drop-off sites.

We sought to understand the magnitude of changes in access to secure dropoff locations: if a Harris County voter relied on public transit, how did having fewer drop-off locations affect their access relative to drivers? How many Harris County residents were affected by the change? And finally, how did targeting voters in Harris and Travis affect drivers' access to voting by race and ethnicity statewide?

\section{Methods}

\section{Accessibility calculations}

We calculated shortest-path travel times from population-weighted census block group centroids to the nearest secure ballot drop-off location before and after the executive order. We geocoded drop-off location addresses obtained from the Texas Secretary of State and Texas Democratic Party websites, resolving any discrepancies using county clerk websites. We reviewed archived versions of the Harris and Travis county clerk websites to identify the drop-off locations proposed before the one drop-off location policy was enacted. Our analysis scripts are available on Github. ${ }^{1}$

Auto travel times were estimated statewide assuming a noon October 27, 2020 departure using ESRI's ArcGIS StreetMap Premium. We calculated average Harris County public transit travel times based on 108 departures randomly selected from within five-minute intervals between $9 \mathrm{am}$ and $6 \mathrm{pm}$ on the same date using the R package r5r (Pereira et al. 2021) and publicly available General Transit Feed Specification (GTFS) data obtained from https://transitfeeds.com/. Transit travel times were only estimated in block groups where at least one trip could be completed within three hours (including walking time) without walking more than $5 \mathrm{~km}$ in the all drop-off location scenario. Block groups that had a feasible transit trip in the all dropoff scenario but not in the one drop-off scenario were assigned a travel time of three hours.

\section{Population measures}

We assembled tract-level Harris County vehicle ownership data from the American Community Survey 2014-2018 five-year estimates and obtained eligible voter counts for block groups statewide by race/ethnicity (US Census Bureau 2021). Voters without vehicle access were estimated by applying tractlevel shares of zero-vehicle households to block groups. We then summarized population-weighted mean travel times for all eligible voters i) by transit (for those without vehicle access) and by automobile (for those with access) in 


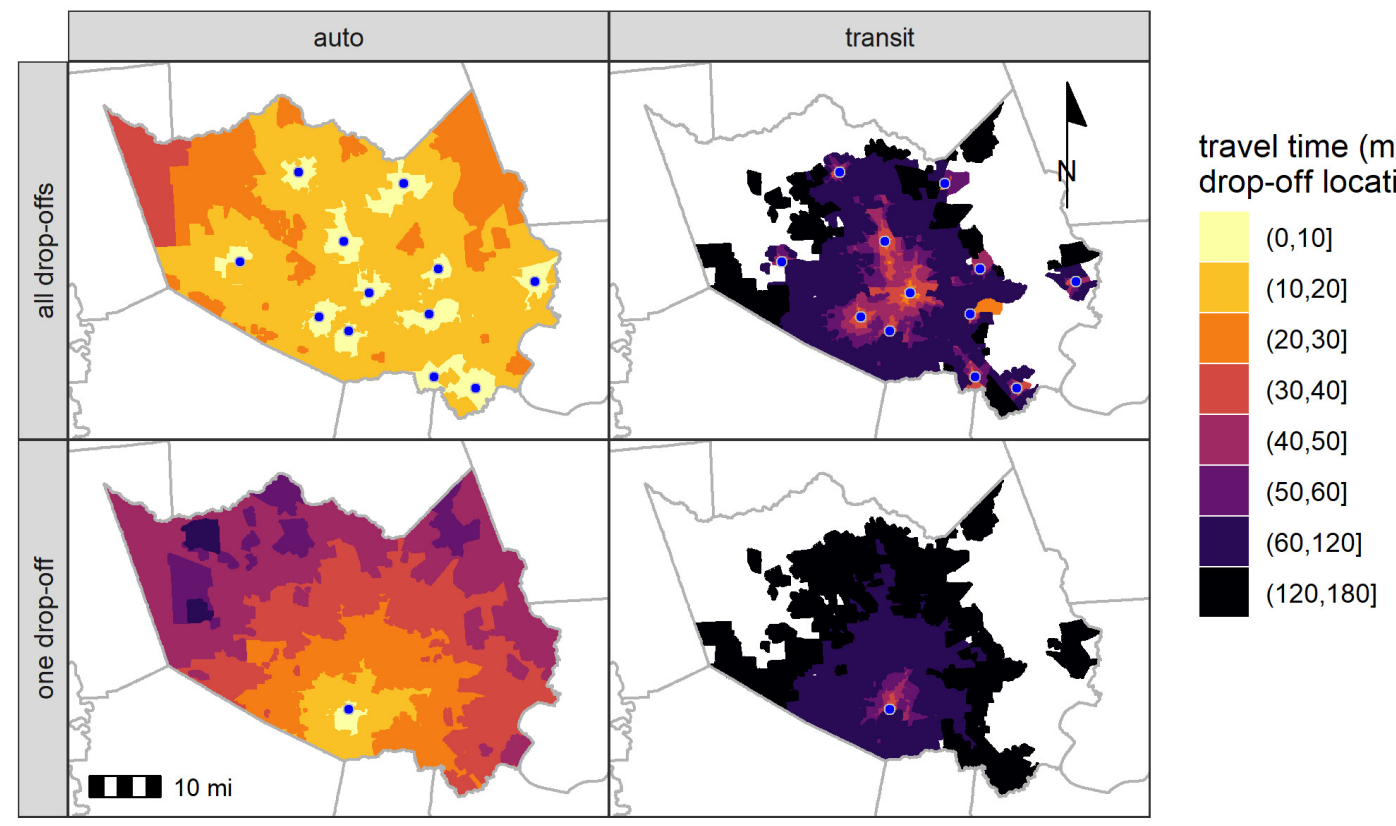

Figure 1. Travel time by automobile and public transit to the nearest secure ballot drop-off location in Harris County for two scenarios: 1) all drop-off locations available (top row) and 2) only one drop-off location available.

Harris County and ii) by automobile for all race and ethnicity categories statewide. We did not evaluate changes in transit access statewide due to limitations in publicly available GTFS data.

\section{Findings}

Figure 1 summarizes driving and public transit travel times to the nearest dropoff location in Harris County before and after the policy change. Accessibility was demonstrably worse for public transit users compared to drivers in all cases-one-way travel times by public transit regularly reached up to three hours while driving times rarely exceeded one hour, even when only one dropoff location was available.

The travel times summarized in Figure 1 can also be assessed using populationweighted averages to evaluate impacts on voters (Table 1). Harris County voters with and without automobile access saw their average travel times worsen substantially with the shift to a one drop-off policy. The impacts of the change on potential transit users compounded the already-long travel times they would have experienced if 12 drop-off locations were available. In fact, the bestcase scenario for public transit travel (56 minutes) was worse than the worst case for drivers ( 32 minutes). For the 143,000 voters without an automobile available, 68,000 would have been able to access their nearest drop-off location within a one-hour transit trip prior to the policy change. This number dropped to 19,000 when the one drop-off location policy was enacted. 
Table 1. Population-weighted mean travel time (minutes) to the nearest drop-off location for Harris County eligible voters by mode and scenario.

\begin{tabular}{|l|l|l|l|}
\hline Mode & All drop-offs & One drop-off & Change \\
\hline $\begin{array}{l}\text { Auto (for voters with } \\
\text { automobile access) }\end{array}$ & 13.8 & 32.3 & $+18.5(134 \%)$ \\
\hline $\begin{array}{l}\text { Transit (for voters without } \\
\text { automobile access) }\end{array}$ & 56.0 & 88.1 & $+32.1(57 \%)$ \\
\hline
\end{tabular}

a There are 143,000 zero-vehicle voters in Harris County. The population-weighted means calculated here do not include the 16,600 who reside in block groups that do not have public transit access within a three-hour one-way trip in the "all drop-offs" scenario.

Table 2. Population-weighted mean automobile travel time (minutes) to the nearest drop-off location for eligible voters in the state of Texas by scenario.

\begin{tabular}{|l|l|l|l|}
\hline Race/ethnicity & All drop-offs & One drop-off & Change \\
\hline Non-Hispanic Asian & 20.1 & 24.8 & $+4.7(23 \%)$ \\
\hline Non-Hispanic Black & 18.2 & 22.4 & $+4.2(23 \%)$ \\
\hline Hispanic/Latinx & 17.3 & 20.0 & $+2.7(16 \%)$ \\
\hline Non-Hispanic white & 18.7 & 21.2 & $+2.5(13 \%)$ \\
\hline
\end{tabular}

Although the one drop-off policy only affected voters in Harris and Travis counties, the substantial number of voters in these counties and their racial/ ethnic composition resulted in a noticeable effect on voters statewide. As demonstrated in Table 2, all voters saw automobile travel times increase under the one drop-off policy, but eligible Asian, Black, and Latinx voters experienced greater increases when compared with eligible white voters.

The impact of these differences extends beyond the potential for disenfranchisement. Black and Latinx people have shouldered a disproportionate share of Covid-19 health impacts (Mackey et al. 2020; Millett et al. 2020). Decreasing access to drop-off locations likely pushed more voters to take longer transit trips or to vote in person, each of which brought an elevated risk of exposure to the virus. Removing drop-off locations forced these at-risk populations to choose between exercising their right to vote and protecting their health.

\section{Acknowledgments}

The authors thank Seth LaRue for assistance with data preparation. 


\section{REFERENCES}

Brady, Henry E., and John E. McNulty. 2011. "Turning Out to Vote: The Costs of Finding and Getting to the Polling Place.” The American Political Science Review 105 (1): 115-34.

https://doi.org/10.1017/S0003055410000596.

Gimpel, J. G., and J. E. Schuknecht. 2003. "Political Participation and the Accessibility of the Ballot Box." Political Geography 22 (5): 471-88. https://doi.org/10.1016/S0962-6298(03)00029-5.

Haspel, Moshe, and H. Gibbs Knotts. 2005. "Location, Location, Location: Precinct Placement and the Costs of Voting." The Journal of Politics 67 (2): 560-73. https://doi.org/10.1111/ j.1468-2508.2005.00329.x.

Mackey, Katherine, Chelsea K. Ayers, Karli K. Kondo, Somnath Saha, Shailesh M. Advani, Sarah Young, Hunter Spencer, et al. 2020. "Racial and Ethnic Disparities in COVID-19-Related Infections, Hospitalizations, and Deaths." Annals of Internal Medicine 174 (3): 362-73. https://doi.org/10.7326/M20-6306.

McDonald, Michael. 2021. “United States Elections Project.” http://www.electproject.org/home/ voter-turnout/voter-turnout-data.

Millett, Gregorio A., Austin T. Jones, David Benkeser, Stefan Baral, Laina Mercer, Chris Beyrer, Brian Honermann, et al. 2020. "Assessing Differential Impacts of COVID-19 on Black Communities.” Annals of Epidemiology 47 (July): 37-44. https://doi.org/10.1016/ j.annepidem.2020.05.003.

Morris, Kevin, and Peter Miller. 2021. "Voting in a Pandemic: COVID-19 and Primary Turnout in Milwaukee, Wisconsin.” Urban Affairs Review. https://doi.org/10.1177/10780874211005016.

Pereira, Rafael H. M., Marcus Saraiva, Daniel Herszenhut, Carlos Kaue Vieira Braga, and Matthew Wigginton Conway. 2021. "r5r: Rapid Realistic Routing on Multimodal Transport Networks with $\mathrm{R}^{5}$ in R.” Findings. https://doi.org/10.32866/001c.21262.

Rabinowitz, Kate, and Brittany Renee Mayes. 2020. "At Least 84\% of American Voters Can Cast Ballots by Mail in the Fall.” The Washington Post, September 25, 2020. https://www.washingtonpost.com/graphics/2020/politics/vote-by-mail-states/.

US Census Bureau. 2021. "Citizen Voting Age Population by Race and Ethnicity.” February 19, 2021. https://www.census.gov/programs-surveys/decennial-census/about/voting-rights/cvap.html. 